librarianship. If elected, my first priority will be to work closely with all ACRL units, other ALA units, and higher education groups to address jointly the challenges facing libraries and higher education.
Editor's note: Thomas Kirk is the librarian of Berea College, Kentucky. Hannelore Rader is director of the Library/Learning Center at the University of Wisconsin, Parkside.

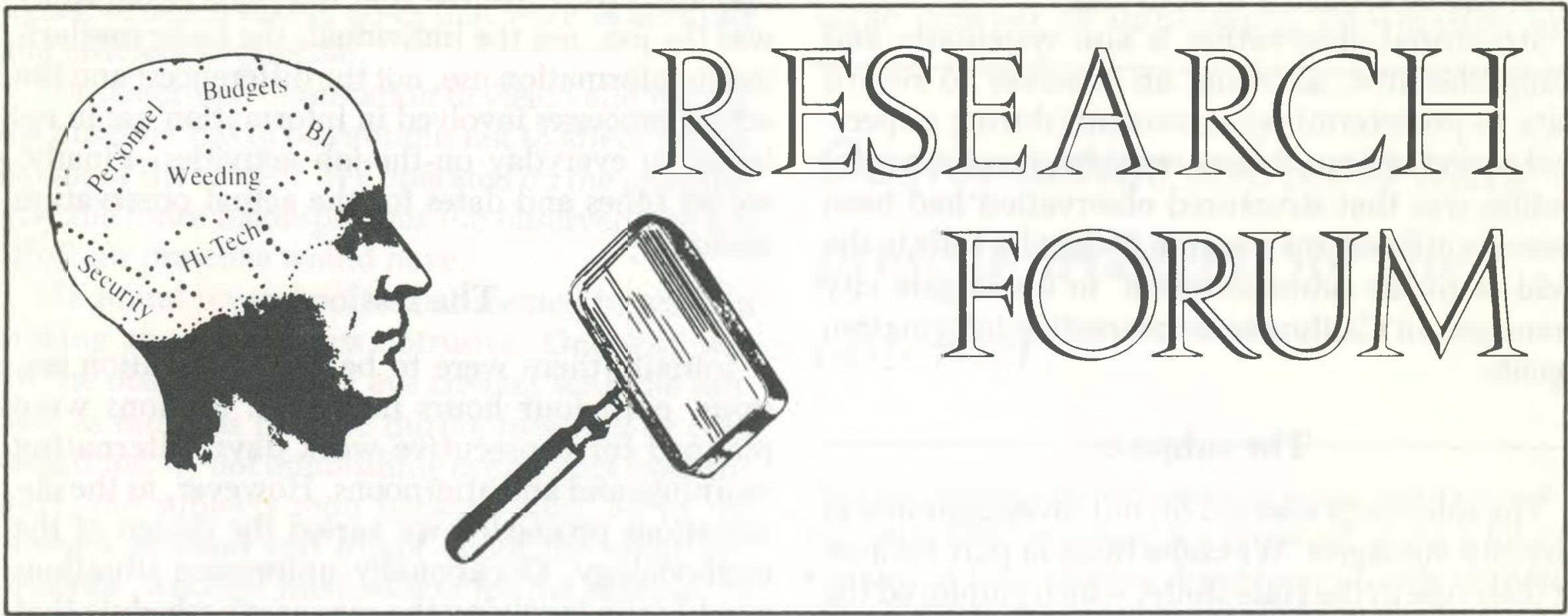

\title{
Structured observation: How it works
}

\author{
By Jack Glazier \\ Research Assistant and Lecturer \\ University of Missouri-Columbia
}

The project described in this article was originally reported at the ALA Library Research Round Table's Research Forum in Dallas and again at the College and University Libraries Section of the Kansas Library Association in Topeka in October 1984. The research project ${ }^{1}$ itself was designed and implemented by Robert Grover, dean of the School of Library and Information Management, Emporia (Kansas) State University, and this author. The project was planned 1) to test structured observation as a research methodology which can be used for research in schools preparing library and information professionals, and 2) to determine the information use patterns of a specific target group as a study of information transfer theory.

\section{Information flow}

Greer has developed a model ${ }^{2}$ in which the transfer of information assumes identifiable patterns influenced by the environment encompassing the social roles of the individual information user.

${ }^{1}$ Robert Grover and Jack Glazier, "Information Transfer in City Government," Public Library Quarterly 5(Winter 1984):9-27.

${ }^{2}$ Roger C. Greer, "Information Transfer: A Conceptual Model for Librarianship, Information Science and Information Management with Implications for Library Education," Great Plains Libraries 20(1982):2-15.
That environment includes patterns of information generation, dissemination, and utilization, as well as a specialized vocabulary, and pertinent names and places singular to the individual's subsociety.

Although Greer's information transfer model provided a theoretical suprastructure, research was still needed to detail more clearly the patterns of information transfer for various subsocieties. Appropriate and innovative methodologies are essential for research of this type. Consequently, one early objective was the development of a methodology for research designed to map the patterns of information transfer for specific subsocieties that would be as workable for graduate students and faculty as for practitioners in the field.

\section{Structured observation}

The primary methodology selected was structured observation. Structured observation is a qualitative research methodology that has been used by the social sciences for several years. It is a methodology in which an event or series of events is observed in its natural setting and recorded by an independent researcher. The observations are structured in the sense that pre-determined categories are used to guide the recording process. It is a methodology that, although not used to our knowledge for library research in this country before, seemed to us to be particularly well suited for information transfer research as we had envisioned it.

As a qualitative research methodology, struc- 
tured observation was desirable for the study of information transfer theory for several reasons, especially its flexibility that allowed us to change the length of the observation periods from what others had previously used. Structured observation could yield specific types of data from an unfamiliar and unrehearsed sequence of activities.

Structured observation is also systematic and comprehensive, allowing an observer to record data in predetermined increments during a specified period of time. A final consideration for our selection was that structured observation had been recently utilized in a research project by Hale in the field of public administration ${ }^{3}$ to investigate city managers in California as interactive information agents.

\section{The subjects}

The subsociety selected for our investigation was also city managers. We chose them in part because of their role in the Hale study, which employed the same basic methodology that we intended to use. Although our study was not to be an exact replication of the Hale study, we believed that there were enough similarities that we would be able to use it to help validate our version of structured observation. Another more pragmatic reason for our selection was the accessibility of the group. There were cities employing the city manager/city commission form of government geographically close enough to make travel feasible on our limited budget.

Two consultants who were acknowledged experts in the area of public administration helped in the actual process of selecting the subjects. Both were asked to submit a ranked list of successful city managers working in Kansas. The consultants recommended a total of ten prospective subjects. Their recommendations were then merged in rank order and the prospective subjects were contacted by letter and phone.

For this study we needed five subjects willing to commit themselves, their staffs, their offices, and their time to our project. We decided to contact subjects one after another until we were able to find five willing to make this investment. Only in three instances were we unable to use a recommended subject. Time involvement was the reason most often given by subjects not wishing to participate in the study.

After they had consented to take part in the project, we visited and interviewed each of the five managers and their staffs prior to beginning the observation sessions. At the meetings we explained more fully the project and its methodology, asked them for candid answers, and conducted a pre-

${ }^{3}$ Martha L. Hale, A Structured Observation Study of the Nature of City Managers (Ph.i. dissertation, University of Southern California, 1983). study interview regarding their perceived information sources. We also scheduled an interview with the manager's secretary at this time, and requested additional data such as the manager's vitae, a copy of his work calendar for the past month, and a copy of the city's organizational chart. In each instance, managers were assured that the focus of the study was the job, not the individual; the basic similarities in information use, not the differences; and the actual processes involved in information use in relation to everyday on-the-job activities. Finally, we set times and dates for the actual observation sessions.

\section{The sessions}

Initially there were to be five observation sessions, each four hours in length. Sessions were planned for consecutive work days, alternating mornings and and afternoons. However, as the observations proceeded we varied the design of the methodology. Occasionally unforeseen situations would arise involving the manager's schedule that would require alterations in the time frame. For example, if a manager was unable to be in his office for a morning session, the session could often be rescheduled for the afternoon, even though it might mean more afternoon sessions than were originally planned. In one instance, the manager had a late morning meeting that extended into the afternoon resulting in an observation session of six hours instead of four. After looking at the data gathered from these sessions we found that these changes did not appear to affect seriously the continuity of the data. This led us to design variation into future observations as a further test of the methodology from the standpoint of both the tools and the actual observer.

In fact what we found was that although the tools held up fine, it was the observer that suffered. The longer days and back-to-back sessions, coupled with the stress of travel, made concentration difficult for the observer at the end of a long day. Variations in the length of the observation sessions appeared to affect the data quantitatively, not qualitatively.

For the actual observations the only tools that were taken into the sessions were two mechanical pencils, a watch, a clipboard, and the recording forms. Two types of forms were employed. The first, called a chronological form, was used to record the moment by moment activities of the subject. Its design was based on a communication model involving sender, receiver, and message. Categories for recording the data included: time of the activity; description of the activity (meeting, phone, conversation, etc.); the medium of communication (telephone, direct personal communication, etc.); description of the apparent purposes and issues of the communication (this was often verified with the city manager during quiet times); and the location of the communication (this category was necessary because not all communication 
took place in the manager's office).

The second form was similar to the chronological form, but with the addition of a category for recording the attention given a particular item (skimmed, read, studied, etc.) and one that gave some indication of the disposition of a specific item (filed, sent on, discarded, etc.). The forms were designed to aid in taking notes that were as accurate and efficient as possible.

For structured observation to yield valid results, the observer has to be cautious not to affect the behavior of the subject. We operated on the principle that the more inconspicuous the observer, the less effect his presence would have.

We found several ways that seemed to work in making an observer less obtrusive. One way was for the observer to limit eye contact with the subjects as much as possible during meetings or conversations. By not establishing eye contact from the start, the subjects soon became involved in the business at hand and forgot about the observer's presence. Another method was for the observer to keep his head down with attention directed strictly on the forms. When I used this technique in our observations it helped in several ways. It took care of the problem of eye contact and in effect took me out of the meetings. In addition, by concentrating solely on notes during meetings, my attention was easier to control and my notes were more detailed and complete.

Another aspect central to controlling the observer's impact on the subject and the environment was positioning the observer in the manager's office. We found that the best location for the observer was behind and slightly to the right of the subject. This location allowed the observer a clear view of the subject's desk as well as the entire room. It also placed the observer close enough to the subject to be able to hear and note phone conversations.

Permission had been given for the observer to have access to the subject's phone calls and mail. Provisions were made for the observer to leave the room if the manager felt the subject being discussed was sensitive. This only happened once and then only for a few minutes. On two occasions the observer was asked not to divulge the specifics of a conversation. In each case the conversation involved the recruitment of new businesses to the community. With these few exceptions, the observer was able to log detailed and comprehensive data.

One problem faced by the observer was long periods of inactivity on the part of the subject. Maintaining attention and yet remaining as inobtrusive as possible during these periods was difficult. On one occasion a manager spent nearly two hours preparing a presentation for the city commission meeting. A majority of the time was spent writing with an occasional recourse to a reference book located on his desk. As the observer in this case, I found remaining alert and attentive without shuffling papers or shifting positions for two hours a formidable task. This experience led us to conclude that data gathering in similar situations would be best accomplished using an alternative methodology such as interviews.

Conversely, a subject that is overly active can also present problems for the researcher. Subjects who are constantly on the move or involved in a large number of impromptu information ex-

\section{Overly active subjects may present problems for the}

\section{observer.}

changes presented difficulties in accurately recording data. One manager we observed spent a large amount of time visiting department heads in their offices. Often this manager would meet individuals in the hallways while moving from one office to another. The ensuing conversations were often short in duration but substantive in content. Note-taking while accompanying a subject along a hallway was difficult. The result was that the observer would have extremely sketchy notes on an encounter that in some instances was a significant aspect of a subject's information transfer pattern. In this situation a solution might be for the observer to carry and use a tape recorder.

Another instance where a high degree of activity became a problem was in meetings. Meetings involving several participants created difficulties for the observer because of the amount of data and the rate at which it was generated. In an effort to deal with this type of situation we tested the use of two observers. We found this worked very well. By putting the notes together we had a complete record of a fast-moving, complex meeting. Another alternative would be to tape record or videotape the meeting if only one observer were available for the session.

When problems arose during observations the observer made a note of the situation so that it could be discussed during a debriefing session. Debriefing sessions were held as soon as possible after each session. They were initially designed for the two principals in the project (Robert Grover and myself) to discuss difficulties encountered during an observation and to make necessary adjustments. We also reviewed highlights of the day while checking observation notes for clarity.

\section{Summary}

Our analysis of the structured observation method showed that it permitted the researcher to gather complete data on complex information interactions. It yielded data with sufficient context to remain fresh, thus allowing researchers more time 
for analysis. In most instances the data was gathered with relationships intact, resulting in clearer explanations. The data clearly defined the information transfer patterns of a specific subsocietycity managers. The success of this project relied to a large degree on the flexibility of the methodology.

Today not only must academic librarians be aware of a wide range of research methodologies to support the research being done by students and faculty, but they also are finding that research and publication have become necessary prerequisites for professional advancement. Unfortunately librarians must deal with time constraints which limit research opportunities.

One consequence of this project is that it validated a methodology that is responsive to the re- search needs of practitioners. Specifically, we found that structured observation is appropriate for use by academic librarians, when used in conjunction with interviews or other data gathering techniques, to determine the information behavior and needs of specific client groups. It is particularly effective for gathering data about client groups for which little is known.

However, for academic librarians the strength of structured observation is its adaptability to restrictive time limitations as well as its wide range of applications. It is a methodology well suited for observing classroom instruction, faculty meetings, curriculum meetings, and the individual work of specific client groups.

\section{ACRL actions, January 1985}

\section{Highlights of the Midwinter meetings of the ACRL Board of Directors.}

T he Board of Directors of the Association of College and Research Libraries met twice during the ALA Midwinter Meeting in Washington, D.C.: on Sunday, January 6, 1985, and Tuesday, January 8 , 1985.

\section{Activity Sections/Board relationship}

The Board voted for the second time to restructure itself to allow for greater representation by activity sections and chapter nominees (see $C \& R L$ News, September 1984, p.393, for details). The proposal will be listed on the ALA ballot this spring for ACRL membership approval.

\section{ALA/ACRL}

The Board received the report of the Task Force on ALA/ACRL and referred it to the Planning Committee to analyze and refer to appropriate ACRL units.

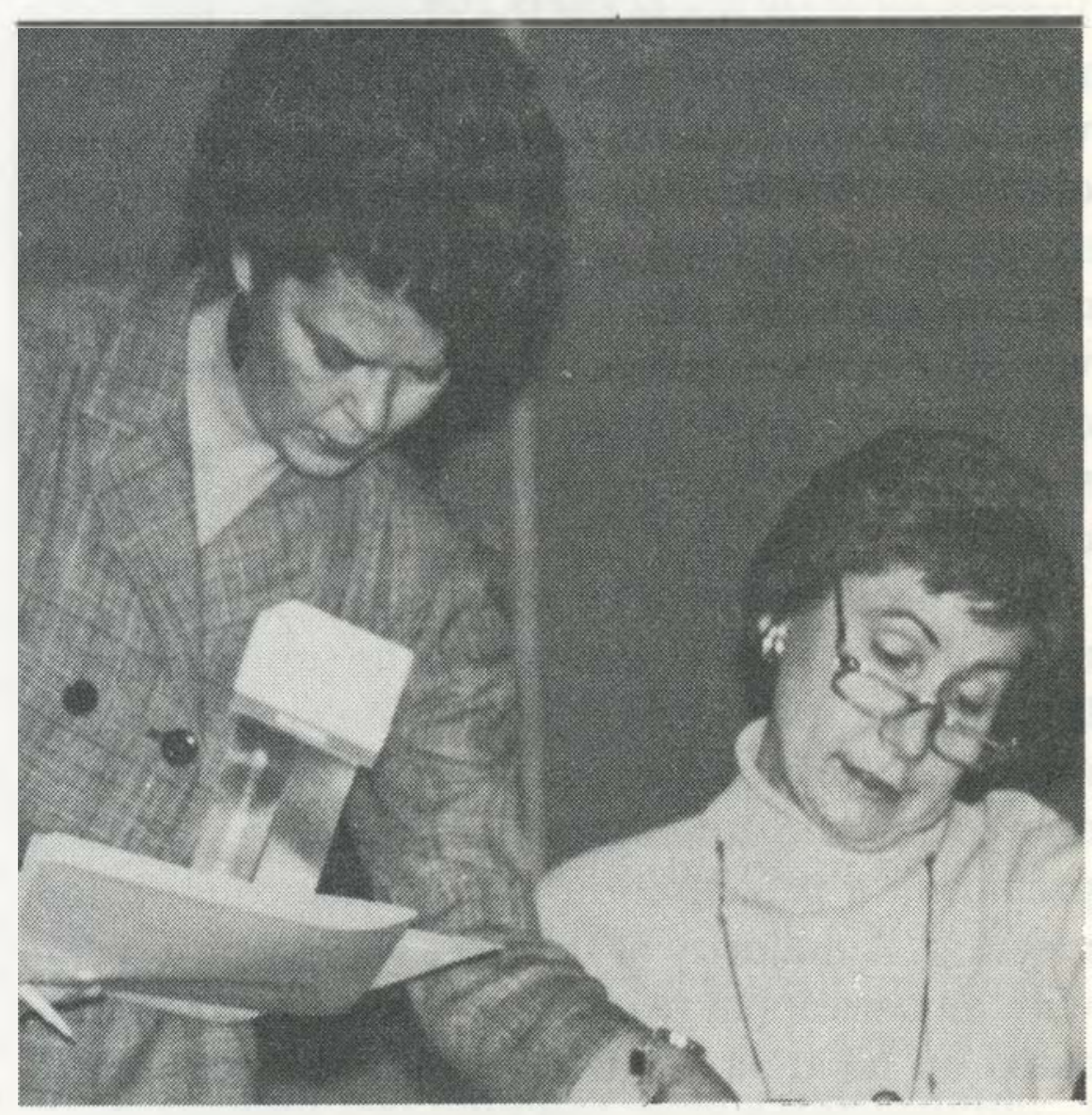

Sharon Rogers and Joan Gotwals 